\title{
Myriam Tsimbidy, La Mémoire des lettres. La lettre dans les Mémoires du XVII siècle
}

\section{Antonella Amatuzzi}

\section{(2) OpenEdition}

\section{Journals}

\section{Edizione digitale}

URL: http://journals.openedition.org/studifrancesi/435

DOI: 10.4000/studifrancesi.435

ISSN: 2421-5856

\section{Editore}

Rosenberg \& Sellier

\section{Edizione cartacea}

Data di pubblicazione: 1 aprile 2015

Paginazione: 142

ISSN: 0039-2944

\section{Notizia bibliografica digitale}

Antonella Amatuzzi, « Myriam Tsimbidy, La Mémoire des lettres. La lettre dans les Mémoires du xvıe siècle », Studi Francesi [Online], 175 (LIX | I) | 2015, online dal 01 avril 2015, consultato il 18 septembre 2020. URL : http://journals.openedition.org/studifrancesi/435; DOI : https://doi.org/10.4000/studifrancesi. 435

Questo documento è stato generato automaticamente il 18 settembre 2020.

\section{(c) $)(1) \Theta$}

Studi Francesi è distribuita con Licenza Creative Commons Attribuzione - Non commerciale - Non opere derivate 4.0 Internazionale. 


\title{
Myriam Tsimbidy, La Mémoire des lettres. La lettre dans les Mémoires du $\mathrm{XVII}{ }^{e}$ siècle
}

\author{
Antonella Amatuzzi
}

\section{NOTIZIA}

MYRIAM TSIMBIDY, La Mémoire des lettres. La lettre dans les Mémoires du XVII eiècle, Paris, Classiques Garnier, 2013, pp. 348.

1 Questo lavoro indaga le interazioni tra i mémoires e la lettera, soggetto raramente studiato finora. In particolare riflette sull'utilizzo della forma epistolare (ormai assunta pienamente a genere letterario nel Seicento) da parte dei memorialisti per rilevare come il materiale epistolare partecipi alla costruzione di una rappresentazione del passato, permettendo di effettuare dei déplacements enunciativi e temporali che rimodellano l'esperienza del tempo. Deve quindi essere considerata una «forme incontournable dans l'écriture des mémoires» (p. 273).

2 Nel primo capitolo, «Corpus insérant des mémoires», l'A. presenta il corpus (che comprende 42 mémoires riguardanti il periodo 1643-1661, cioé la minorité di Luigi XIV), definendone i criteri di selezione. Nel secondo, «Typologie des lettres insérées dans les mémoires», stabilisce la natura e le categorie di lettere più rappresentate nel corpus. Si tratta essenzialmente di lettere di carattere pubblico o politico (e non appartenenti alla sfera intima o privata) presentate come autentiche, la cui presenza allinterno del racconto memorialistico risponde ad esigenze dimostrative e/o informative e non a scelte estetiche. Nel terzo, «La lettre dans la composition des mémoires», si sofferma sul ruolo delle lettere nella narrazione e sulle modalità di inserzione utilizzate dai memorialisti (fusione tra discorso epistolare e discorso memoriale o, invece, eterogeneità delle lettere). Questa operazione di 'tissage et démontage du texte épistolaire' (p. 113) riflette due concezioni diverse della scrittura della storia (una 
tendente alla narratività e una più scientifica) e provoca un cambiamento di livello e di registro nel récit imponendone una lettura frammentata. Nel quarto capitolo, «L'énonciation épistolaire: jeux et enjeux» si concentra sulla variazione che l'introduzione di lettere provoca, a livello enunciativo, nella scrittura dei mémoires. La forma epistolare, messa in scena enunciativa che imita una conversazione familiare con una persona assente, crea una situazione comunicativa complessa, in cui il destinatario dei mémoires diventa spettatore e il narratore cede la parola, occultandosi. Nel quinto, «La lettre dans le régime et la conduite de la narration» esamina il ruolo delle lettere nella narrazione dei mémoires. Pur rivestendo la doppia funzione di documento storico e di fonte di fictionalité necessaria alla narrazione, la lettera vede il suo statuto alterato: perde la sua autonomia per diventare l'elemento di uno scenario. Nel sesto ed ultimo capitolo, «La lettre ou les autoportraits des mémorialistes», osserva come le lettere, attraverso i protocolli e le scenografie sociali mobilitati, entrino nella poetica del genere dei mémoires e lo modifichino, accentuando il ruolo del memorialista e complicandone l'immagine.

3 Completano l'opera gli elenchi delle lettere contenute nei mémoires analizzati e una utile bibliografia. 